\title{
$\mathrm{PH} 105$
}

Muñoz Cosme, A.

\section{La intervención en el patrimonio arquitectónico en España, 1975-2015}

Murcia: Universidad de Murcia, 2020

Siete son el número de capítulos que componen el presente libro, editado en 2020; los suficientes para que Alfonso Muñoz Cosme, su autor, sistematice los últimos cuarenta años (1975-2015) de la historia de la intervención en el patrimonio arquitectónico español.

El primer capítulo de la publicación aborda el progreso conseguido en el marco legislativo e institucional para la defensa y conservación del patrimonio. La normativa vigente en 1975 (Ley de 13 de mayo de 1933, sobre defensa, conservación y acrecentamiento del Patrimonio Histórico-Artístico Nacional) se encontraba anticuada para los nuevos tiempos de cambio: la Transición. Con la aprobación de la Ley 16/1985 de Patrimonio Histórico se proporciona un gran impulso a la restauración y conservación del patrimonio histórico español. Por otro lado, el capítulo segundo recoge el debate teórico que se ha desarrollado de cara a la intervención arquitectónica en nuestro país, apartado que, según el autor, ha sido menos fecundo que la práctica. edit.um

LA INTERVENCIÓN EN EL. PATRIMONIO ARQUITECTÓNICO EN ESPAÑA. 1975-2015 Alfonso Muñoz Cosme

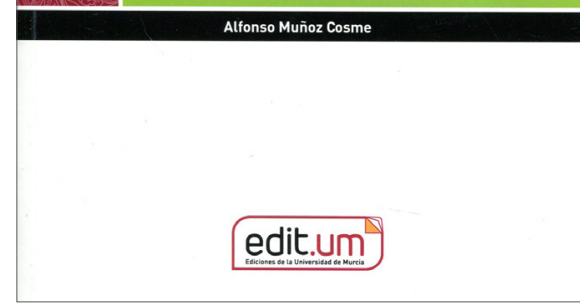

Los capítulos sucesivos (del 3 al 6) exponen por decenios los criterios de intervención predominantes, acompañados de un abundante número de aplicaciones prácticas.

De 1975 hasta 1985, paradójicamente, estamos ante las dos caras de una moneda, ya que conviven criterios que, por un lado, desean la ruptura con las intervenciones de corte historicista que caracterizaron los años del Régimen, con otros que postulan la pervivencia de tales historicismos. Del mismo modo, resulta digno de mención la puesta en marcha de planes de rehabilitación de los centros históricos de las ciudades, con carácter interdisciplinar; dinámica arengada por escritos internacionales (Carta de Europa) o ejemplos paradigmáticos como la intervención sobre el centro histórico de Bolonia.

Entre 1985 y 1995 los criterios oscilan entre "analogía crítica" y "restauración objetiva". El primero, acuñado por Ignasi de Solà Morales, pretende "definir una forma de intervención en la que el nuevo diseño, aunque creativo y libre viene condicionado por la preexistencia". La "restauración objetiva" pretende un método que supere las modificaciones de carácter subjetivo, aquellas en las que los criterios se adaptan a la especificidad del inmueble. Por estos años se llevan a cabo las primeras intervenciones en el paisaje y en sus estructuras, consolidándolas para crear "ruinas visitables". 
Paralelamente, anida en la mentalidad colectiva el deseo de preservar el patrimonio industrial, culminando en la materialización del Plan Nacional de Patrimonio Industrial (año 2000).

La gran ruptura con los criterios de intervención anteriormente establecidos tiene lugar entre 1995 y 2005: la arquitectura de nueva adición debía producir un choque sobre la arquitectura preexistente. Esta concepción se opondría a los principios de intervención demandados en la Carta de Cracovia (2000), que postulaba el carácter intrínseco de la arquitectura existente en relación a un proyecto global nuevo.

Finalmente, en la década de 2005-2015 se han dado cita criterios que defienden que los conceptos de sobriedad expresiva, minimalismo y sostenibilidad han de primar en las intervenciones. Igualmente no podemos pasar por alto el valor que en los últimos tiempos se le ha dado a la conservación preventiva.

Tras esto, el último de los capítulos se reserva para unas conclusiones y proyección de futuro para la restauración arquitectónica.

A nuestro parecer, este libro, de forma clara y concisa, resume el transcurrir de cuarenta bulliciosos años en el ámbito de la intervención sobre el patrimonio arquitectónico español; la división de los capítulos en breves subapéndices ayuda a la creación de esta sucinta pero completa visión. Para este dificultoso camino hemos contado con la noción de Patrimonio como medio de tracción, concepto en constante evolución y al que, si se nos permite la expresión, aún le queda combustible por quemar.

Jesús López Gómez | Estudiante

URL de la contribución <www.iaph.es/revistaph/index.php/revistaph/article/view/5051> 